\title{
Method of debris flow prediction based on a numerical weather forecast and its application
}

\author{
F. Wei ${ }^{1}$, K. Gao ${ }^{1}$, P. Cui ${ }^{1}$, K. Hu ${ }^{1}$, J. Xu ${ }^{2}$, G. Zhang ${ }^{2}$ \& B. Bi ${ }^{2}$ \\ ${ }^{1}$ Institute of Mountain Hazards and Environment, \\ Chinese Academy of Sciences \\ ${ }^{2}$ National Meteorology Center of Chinese Meteorological Administration
}

\begin{abstract}
Debris flow is one of the main natural hazards in mountains areas of China, especially in south-western China. Because the region with debris flow hazard is wide and the number of debris flow valleys is great, debris flow prediction is an important measure of debris flow disaster mitigation. A prediction method of debris flow based on a numerical weather forecast was carried out. According to the conditions of debris flow formation including energy, incompact debris and inducing factors (rainfall), the relative height, stratum, fault, land use, total rainfall consisting of effective antecedent precipitation and forecasting precipitation, and maximum precipitation intensity of 1 hour were selected as factors for prediction of debris flow. A prediction model was set up with these factors and extension theory which is a new kind of knowledge system based on the concepts of matter-element and extension set. In the model, total rainfall and maximum rainfall intensity of 1 hour obtained by a numerical weather forecast are the principle input variables. South-western China including Sichuan, Yunnan, Guizhou and Chongqing which has heaviest debris flow disasters in China was selected as a case study region. An application system of debris flow prediction based on the model was developed with GIS (ArcGIS) for the study region.

Keywords: debris flow, prediction, numerical weather forecast, south-west of China.
\end{abstract}




\section{Introduction}

Debris flow forecast is an effective measure supplied to government to make decision of disaster mitigation and public to avoid disasters. It is divided into extend-range forecast, mid-range forecast and short-range forecast depending on the forecast period, as well as forecast for a region and for a given valley depending on the forecast district. Among them, regional short-range forecast is the most important one because it gives a warning of debris flow in a specific region at a specific time. And this is the focus of discussion here.

Many researches on regional long-range forecast of debris flow have been developed, but only a few on the short-range one. Cannon [1] analyzed the regional rainfall-threshold conditions for debris flow activity. Tan [2] developed a forecast model for Panxi region of Sichuan based on determination of the threshold precipitation inducing debris flow. Wilson [3] researched the rainfall/debris flow threshold values along the U. S. Pacific coast with analyzing broad-scale variations in long-term precipitation climate. Wang [4] carried out a method of forecast for Beijing mountains region based on the critical rainfall of debris flow occurrence. Wieczorek [5] assessed debris flow hazards with remote sensing of rainfall. Four disaster events were analyzed in Wieczorek's research, and the advantages and limitations of remote sensing of rainfall for landslide hazards analysis were discussed. However, no definite model was established in his research. According to the analysis on the natural conditions of debris flows developing and the possible rainfall in future 24 hours, Wei [6] set up a prediction system to supply regional debris flow forecast and assessment of possibility of debris flow in each valley in the mountains area of Beijing. Most of researches above are only theoretical and a practical forecast system is impossible without product of rainfall forecast.

In order to develop a practical forecast system, Chinese Academy of Sciences and China Meteorological Administration make a cooperation research on debris flow forecast. The objective is to develop a regional short-range forecast system based on numerical weather forecast, and south-west of China was selected as case study region including Yunnan, Sichuan, Guizhou and Chongqing which has heaviest debris flow disasters in China was selected as case study region.

\section{Principle of debris flow forecast}

\subsection{The basic principle of debris flow forecast Introduction}

Three conditions are necessary for debris flow formation: energy (topography), unconsolidated debris material and water source. Energy is determined by relative height and slope. The magnitude of unconsolidated debris material is influenced by geology, land use and climate, and so on. Water resource includes rainfall, thaw water of glacier and reservoir. Because most of debris flows are triggered by rainfall, rainfall is considered as the only source here. In a large region, both energy and unconsolidated debris material and water source can be considered as basic conditions because they are nearly invariant in a long period. 
However, rainfall varies every day. So the debris flow is the result of the rainfall and therefore the principles of regional short-range debris flow forecast are:

- Monitoring and analyzing rainfall of the preceding period;

- Predicting rainfall in several to 24 hours;

- Assessing the probability of debris flow occurrence based on the rainfall conditions;

- The large region should be divided into small units to assess the debris flows.

There are two ways to divide the region into small units: one is based on catchments and the other uses grid method. It's very difficult to determine the size of catchment or the level of branch of watershed to be chosen as the assessment unit because debris flow can develop in different levels of branches and different scales of watersheds. So the grid method is an available measure for the region division. According to the research of Wei and Xie [7], the area of $91 \%$ of debris flow valleys in China is under $60 \mathrm{~km}^{2}$, and most of them concentrate in $10 \mathrm{~km}^{2}$. So the size of grid can be defined as $3 \mathrm{~km} \times 3 \mathrm{~km}$.

\subsection{Factors of debris flow forecast}

According to the formation conditions of debris flow, impacts of endogenic and exogenic forces on the region and the principle of forecast, following factors are selected for regional short-range forecast of debris flow.

\subsubsection{Factors of energy conditions}

The energy conditions include energy of position and energy gradient. The former is reflected by the relative height of each unit and the latter by the slope which can be estimated approximately with the relative height and the size of the grid. Because the size of every grid is the same, the relative height is closely related to slope and therefore can reflect the energy gradient approximately.

\subsubsection{Factors of unconsolidated debris material}

Of course, the magnitude of unconsolidated debris material is the best to assess debris flow but there is no available measure to get the magnitude in a large region. The factors impacting on forming debris material have to be taken instead. Stratum is the first important factor. The lithologic characters and geologic age of the stratum determine the resistance to weathering and weathering intensity of the exposed rocks. Fault, one of the results of geological tectonic movement, destroying rocks, is the second important factor. Land use, a composite factor influencing debris material, not only reflects the influence of vegetation, but also indicates the action of human activities.

\subsubsection{Factors of rainfall conditions}

Rainfall conditions consist of quantity and intensity of rainfall, which impact on debris flow formation jointly. For the limitation of the available rainfall forecast method, the maximum rainfall in one hour is selected as the factor indicating intensity of rain, although that in half hour or 10 minutes is more effective. Quantity of rainfall includes two parts as illustrated by figure 1. A is the 
antecedent rainfall consisting of $\mathrm{C}$ (none-effective antecedent rainfall) and $\mathrm{D}$ (effective antecedent rainfall), and $\mathrm{B}$ is the expected future rainfall consisting of $\mathrm{E}$ (expected effective rainfall) and $\mathrm{F}$ (expected surplus rainfall). According to this, the effective rainfall quantity should be the sum of D and E. However, this should be defined as the sum of D and B in practice because there is no way to determine the point of debris flow forming.

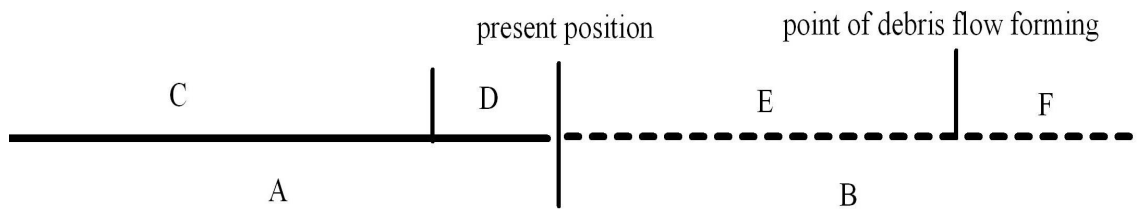

Figure 1: $\quad$ Illustration of quantity of rainfall.

\section{Method of regional short-range forecast of debris flow}

\subsection{Model of regional short-range forecast}

Previous researches tried to determine the critical rainfall of debris flow formation for making a deterministic prediction. However, this is almost impossible for regional forecast because the critical rainfall of debris flow formation is controlled by many factors of the underlying surface, varies in different regions, even in different parts of a certain region. In other words, at present, it is a feasible method to estimate the probability of debris flow formation under a coming rainfall in a region through setting up an assessment model with the major factors influencing debris flow formation. Based on the analysis above, six factors are chosen for assessing the probability: relative height $\left(X_{1}\right)$, stratum $\left(X_{2}\right)$, fault $\left(X_{3}\right)$, landuse $\left(X_{4}\right)$, total rainfall $\left(X_{5}\right)$ and rainfall intensity $\left(X_{6}\right)$. Under the action of these factors in different manners, there are different probabilities of debris flow occurrence: $B_{j}(j=1,2,3, \ldots, \mathrm{m})$. In order to determine the probability, a standard matter-element model is designed as follows.

$$
R_{0}=\left[\begin{array}{ccc}
B & X_{1} & x_{1} \\
& X_{2} & x_{2} \\
& \vdots & \vdots \\
& X_{6} & x_{6}
\end{array}\right]
$$

where, $x_{1}, x_{2}$ and $x_{6}$ are the values of factors $X_{1}, X_{2}$ and $X_{6}$ respectively.

For any behaviors of the factors $R$, in the standard matter-element model $R_{0}$ the relevance between $R$ and the behaviors corresponding to probabilities of debris flow occurrence, $\mathrm{K}_{\mathrm{j}}(\mathrm{P})$, can be calculated by

$$
K_{j}(P)=\sum_{i=1}^{6} \alpha_{i} K_{j}\left(x_{i}\right)
$$


where $\alpha_{\mathrm{i}}$ is the weight of factor $X_{i}$ among the six factors, $K_{j}\left(x_{i}\right)$ is the relevance between the behavior of factor $X_{i}$ in $R$ and the behavior of $X_{i}$ corresponding to probabilities of debris flow occurrence in $R_{0}$.

If $K_{k}(P)=\max _{k \in\{1,2, \cdots, m\}} K_{j}(P)$, the probability of debris flow occurrence is $B_{k}$.

\subsection{Defining probabilities of debris flow occurrence}

The result of regional debris flow forecast is described by the probability of debris flow occurrence. However, the accurate probability is unavailable from the debris flow prediction model based on statistics. The result thus has to be described by several space intervals of the probability. Each interval represents a grade of the probability. This describing form is just suitable for releasing the prediction with different colors by the authorities.

Because the regional forecast is released to public by China Meteorology Administration (CMA), the result of debris flow forecast is divided into five grade intervals $(0-0.2,0.2-0.4,0.4-0.6,0.6-0.8,0.8-1)$ to meet the classification standard of CMA. The first and second grades are not released to public, and the third, fourth and fifth grades are released to public with yellow, orange and red.

\subsection{Getting the factors of rainfall based on numerical weather forecast}

In the forecast scale, only total rainfall $\left(X_{5}\right)$ and rainfall intensity $\left(X_{6}\right)$ are the variables, and therefore they are crucial for the accuracy of forecast. And a model of numerical weathering forecast provides a measure to get $X_{5}$ and $X_{6}$. It is the WRF (the Weather Research and Forecasting Model), a next-generation numerical weather prediction system, which is designed to serve both operational forecasting and atmospheric research and developed by the National Center for Atmospheric Research, the Air Force Weather Agency, the Naval Research Laboratory, Oklahoma University and the Federal Aviation Administration of USA. It features multiple dynamical cores, a 3-dimensional variational (3DVAR) data assimilation system, and a software architecture allowing for computational parallelism and system extensibility. WRF is suitable for a broad spectrum of applications across scales ranging from meters to thousands of kilometers, and runs in National Meteorology Center of Chinese Meteorological Administration (NMC).

WRF can offer the total quantity of rainfall and rainfall of each hour in future 12 hours in NMC. The maximum rainfall of each hour is the rainfall intensity $\left(X_{6}\right)$ expected in the debris flow forecast model. The total rainfall $\left(X_{5}\right)$ in the model consists of effective antecedent rainfall and expected effective rainfall. In practice, the expected effective rainfall is replaced with expect future rainfall which is just the total quantity of rainfall in future 12 hours given by WRF. And the effective antecedent rainfall $R_{a}$ is estimated with the equation of Senoo [8]

$$
R_{a}=\sum_{t=1}^{14} a_{t} R_{t}
$$


where $R_{t}$ is the daily-rainfall on the $t$ th-day before monitored by meteorological stations, and $a_{t}=0.5^{t / T}$ is decay rate, where $T$ is the half life of rainfall.

\section{Application of regional short-range debris flow forecast}

\subsection{Introduction of case study region}

The study region including Yunnan, Guizhou, Sichuan and Chongqing is the most serious region of debris flow in China. It consists of the east part of Tibetan Plateau, Yun-Gui Plateau, and Sichuan Basin, where the number of debris flow valleys is great. Most of debris flow valleys are distributed mainly in Hengduan Mountains, the lower reaches of Jinsha River and mountains area of western Sichuan (Figure 2), along five large rivers (Nujiang River, Lancangjia River, Jinsha River, Yalongjiang River and Minjiang River) and their principal branches. In the region, precipitation is rich in summer influenced by monsoon from both Pacific and Indian Ocean. Most of debris flow disasters are triggered by rainfall, and the frequency debris flow is very high every year.

\subsection{The applied system of debris flow forecast in south-western China}

\subsubsection{Platform of the applied system developed}

- Hardware platform Personal computer with P4 CPU.

- Software platform Microsoft Windows XP Professional and ArcGIS 9.0 of ESRI.

\subsubsection{Functions of the applied system}

The system is developed for regional short-range forecast, including 5 main functions: precipitation data processing, debris flow forecast, map of forecast result drawing, data maintenance and file operation.

- Precipitation data processing Function of precipitation data processing prepares the data of total rainfall and rainfall intensity for debris flow forecast. The data of antecedent rainfall observation transmitted from the meteorological stations are analyzed to the effective antecedent rainfall and then interpolated into a map of effective antecedent rainfall distribution. Because the format of quantity of rainfall and rainfall intensity in coming 12 hours from WRS is invalid for this system, it has to be transformed to the valid format of ArcGIS.

Debris flow forecast Debris flow forecast is the key function of the system. It executes the model of debris flow forecast with the spatial analyst tools of ArcGIS and six maps of the factors to identify the probability of debris flow occurrence in every grid with $3 \mathrm{~km}$ length of side.

Debris flow forecast mapping The forecast result is represented by a grid image; every grid is assigned a value of the probability of debris flow 
occurrence. However, it is not suitable for release to public directly because there might be many isolated grids with high probability. These isolated grids must be analyzed comprehensively with the DEM and the distribution map of debris flow valleys and then a map marked three category regions with red, orange and yellow is carried out by this function. The last step is to add the residential area, highway, railway etc. on the map for making the final map of debris flow forecast.

- Data management This function is designed to clean off temporary folds and intermediate result, delete outdated data and backup the data of debris flow forecast results.

File operation This function is designed to save files, add data, print map and import and export data.

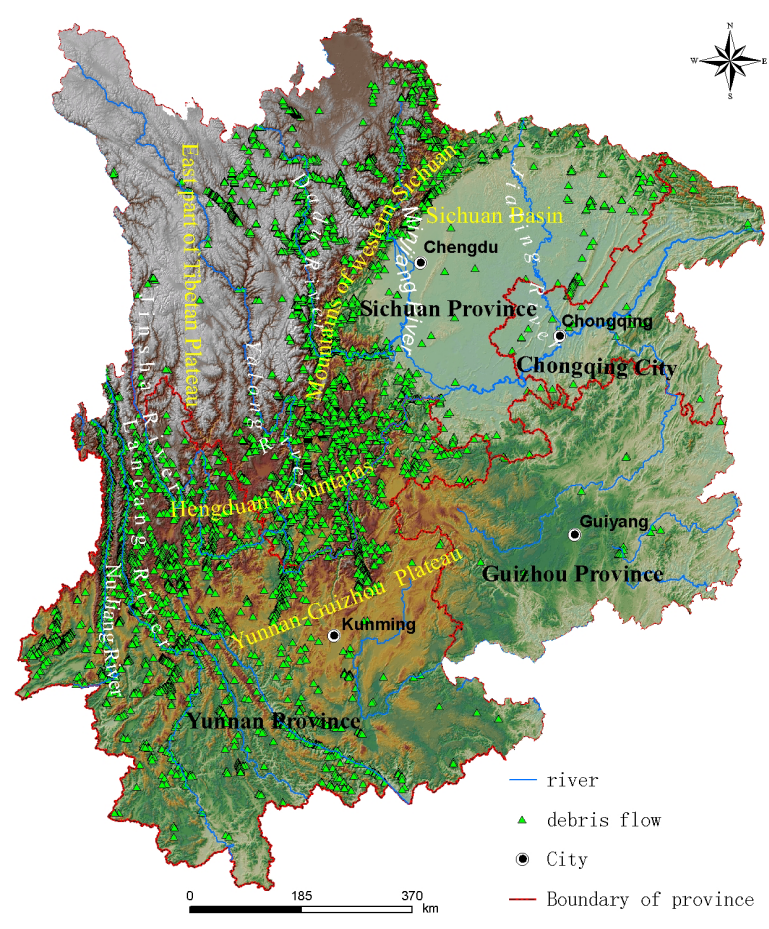

Figure 2: $\quad$ The study region and distribution of debris flow valleys.

\subsubsection{Time scale of forecast}

The WRF can offer rainfall forecast in coming 36 hours while the time scale of debris flow forecast is limited to 12 hour, this is because the accuracy of the 
rainfall forecast is low and even lower along with time expanding. So the system of debris flow forecast runs twice per day. According to the usual practice of Central Meteorology Office of China, the first time is from 8:00 to 20:00 and the second time from 20:00 to 8:00 of tomorrow.

\subsubsection{Determining the standard total rainfall and rainfall intensity}

In the debris flow prediction model, the total rainfall $\left(X_{5}\right)$ and the rainfall intensity are two crucial parameters. They were determined by analyzing past data of debris flow occurrences. 325 debris flow events with complete rainfall process records in the study region were selected to determine the standard total rainfall and rainfall intensity. According to the statistic analysis of past debris flow events, the standard total rainfall and rainfall intensity corresponding to different probabilities of debris flow occurrence are determined as table 1.

Table 1: $\quad$ The standard total rainfall and rainfall intensity.

\begin{tabular}{|c|c|c|c|c|c|}
\hline Probability & $0-0.2$ & $0.2-0.4$ & $0.4-0.6$ & $0.6-0.8$ & $0.8-1$ \\
\hline$X_{5}(\mathrm{~mm})$ & $0-20$ & $20-60$ & $60-120$ & $120-200$ & $200-1000$ \\
\hline$X_{6}(\mathrm{~mm})$ & $0-3.0$ & $3.0-7.5$ & $7.5-10.0$ & $10.0-17.5$ & $17.5-50$ \\
\hline
\end{tabular}

\subsection{Test running of the forecast system}

This forecast system was run in National Meteorology Center of Chinese Meteorological Administration. in the rainy season from June to October 2005 for testing its accuracy. The system supplied the result of forecast with a map marked three colors, red, orange and yellow, as figure 3. Red represents the probability of debris flow between $0.8-1$, orange, 0.6-0.8, and yellow, 0.4-0.6. Figure 3 is the forecast result of 29 June 2005. In the debris flow disasters report of government, there are 7 debris flow disasters (marked in figure 3 with stars) on that day. Depending on the test running analysis, following conclusions are drawn up:

- Most of debris flow disasters appeared in red and orange regions, but a few disasters appeared in yellow regions, even outside these three colors. The result of forecast is reliable on the whole, and the method is feasible for regional debris flow forecast.

- The accuracy of forecast is perfect for the disasters of debris flow induced by regional rainfall in large scale, but it is imperfect for that induced by local rainfall, especially for that induced by storm rainfall due to local severe convective weather.

- When disasters appeared in the regions unmarked, most of the forecast rainfalls were less but the actual observation rainfalls were much. So most errors of this kind were caused by rainfall forecast errors.

The accuracy of rainfall forecast is crucial in influencing the accuracy of 
forecast, especially for the debris flow disasters triggered by local rainfall. In order to avoid the result that debris flows appear in unmarked regions, strong local rainfall should be monitored by Doppler meteorological radar.

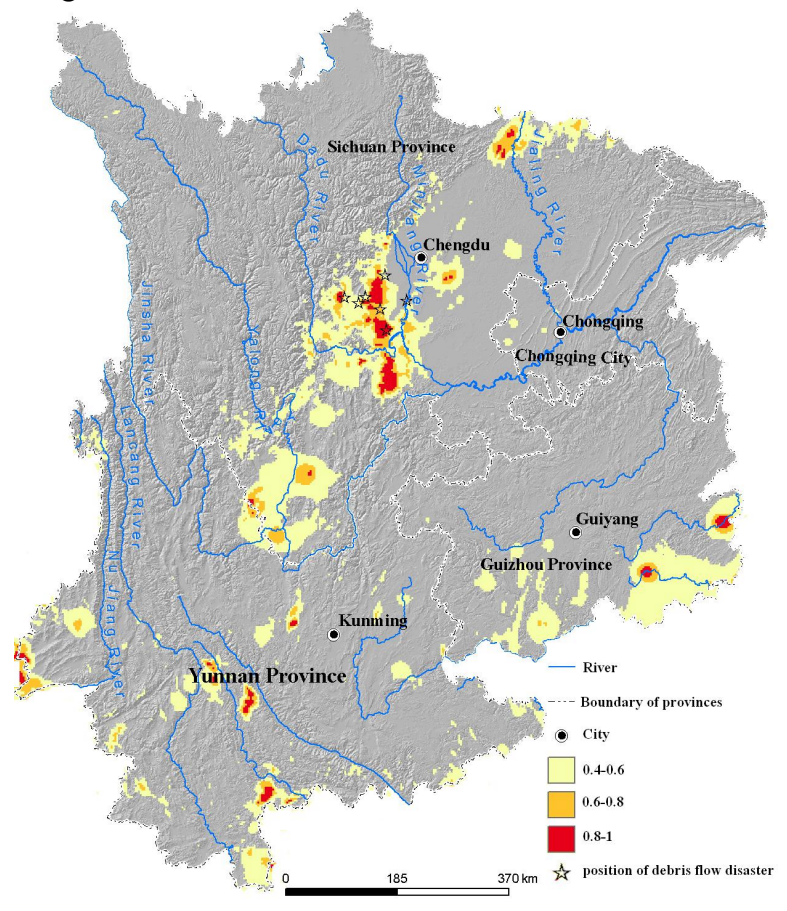

Figure 3: The result of debris flow forecast on 29 June 2005.

\section{Conclusions}

The following conclusions are drawn from above analysis and the test run of the system of debris flow forecast applied to south-west of China in the CMOC.

1. It is an effective measure for regional debris flow forecast at present to estimate the grade of probability of debris flow occurrence by analyzing the coming rainfall and other factors of the underlying surface comprehensively.

2. Numerical weather forecast is the best way of offering rainfall forecast to regional debris flow forecast because its rainfall forecast is relative accurate and has long effective period.

3. The result of the applied system turns up trumps for debris flows induced by large regional rainfall, but it's not good for debris flows due to local rainfall or the storm rainfall induced by local severe convection weather.

4. The data of antecedent rainfall monitored by meteorological stations which are set up on the towns along the river valleys can't reflect the real distribution of 
antecedent rainfall, and the interpolation analysis by ArcGIS may cause error because it doesn't consider the influence of evolution variation. All the errors of influence the accuracy of debris flow forecast. This problem has to be resolved by other measurements in further research.

\section{Acknowledgements}

This research is supported by the Knowledge Innovation Program of Chinese Academy of Sciences (KZCX3-SW-352), Institute of Mountain Hazards, Chinese Academy of Sciences and the Open Foundation of Weather Forecast System Laboratory, National Meteorology Center of Chinese Meteorological Administration.

\section{References}

[1] Cannon, S. H., Regional rainfall-threshold conditions for abundant debrisflow activity. Landslides, floods, and marine effects of the storm of January 3-5, 1982, in the San Francisco Bay region, California, U. S., Geological Survey Professional Paper no. 1434, eds. Ellen, S. D. \& Wieczorek, G.. F. pp. 35-42, 1988.

[2] Tan, W., Wang, C., Yao, L. et al., Regional rainfall/debris flow and landslide prediction, Press of Sichuan Science and Technology: Chengdu, pp. 185-241, 1994. (in Chinese)

[3] Wilson, R. C., Normalizing rainfall/debris-flow thresholds along the U. S. Pacific coast for long-term variations in precipitation climate. Proc. of the $1^{\text {st }}$ Int. Conf. On Debris Flow Hazard Mitigation: Mechanics, Prediction, and Assessment, ed. C. L. Chen, New York: ASCE, pp. 32-43, 1997.

[4] Wang, L., Yu, Z., Prediction of mountain torrents and debris flows disasters, Press of China Forest: Beijing, pp. 119-219, 2001. (in Chinese)

[5] Wieczorek, G.. F., Coe, J. A. \& Godt, J. W., Remote sensing of rainfall for debris flow hazard assessment. Proc. of the $3^{\text {rd }}$ Int. Conf. On DebrisFlow Hazards Mitigation: Mechanics, Prediction, and Assessment, eds. D. Rickenmann \& C. L. Chen, Millpress: Rotterdam, pp.1257-1268, 2003.

[6] Wei, F., Tang, J., Zhong, D. et al., Debris flow forecast combined regions and valleys and its application. Journal of Mountain Science, 22(3), pp. 321-325, 2004. (in Chinese)

[7] Wei, F., and Xie, H., Model of Fuzzy information for debris flow risk factor zoning. Journal of Chinese Soil and Water Conservation, 30(4), pp. 273-277, 1999.(in Chinese)

[8] Senoo, K., Godai, H., Hara, Y. et al., Rainfall indexes for debris flow warning evacuating program. Shin-Sabo, 38(2), pp. 16-21, 1985. (in Japanese) 